Article

\title{
Performance Analysis of KPI's of a 4G Network in a Selected Area of Port Harcourt, Nigeria
}

\author{
A.C. Ekeocha ${ }^{1}$, P. Elechi ${ }^{2}{ }^{*}$, O.C. Nosiri ${ }^{3}$ \\ ${ }^{1}$ Department of Computer Science, University of Port Harcourt, Port Harcourt, Nigeria \\ ${ }^{2}$ Department of Electrical/Electronic Engineering, River State University, Port Harcourt, Nigeria \\ ${ }^{3}$ Department of Electrical/Electronic Engineering, Federal University of Technology, Owerri, Nigeria \\ *Correspondence: elechi.promise@ust.edu.ng
}

How to cite this paper: Ekeocha, A.C..; Elechi, P.; Nosiri, O.C. (2021) Performance Analysis of KPI's of a 4G Network in a Selected Area of Port Harcourt, Nigeria. World Journal of Electrical and Electronic Engineering, 1(1), 44-50. Retrieved from https://www.scipublications.com/journal/index.php/wjeee/article/view/133

Received: August 20, 2021 Accepted: September 24, 2021 Published: September 25, 2021

Copyright: (c) 2021 by the authors. Submitted for possible open access publication under the terms and conditions of the Creative Commons Attribution (CC BY) license (http://creativecommons.org/licenses /by/4.0/).

\begin{abstract}
The introduction of 4G LTE communication technology was basically designed to meet the increasing demand by users for high-quality multimedia services, data communication speed and improved quality of service (QOS). It is pertinent to note that, with an ever-increasing subscriber base, it is essential to assess and analyze the network performance. To perform this task, there is a need to use the key performance indicators (KPI). This research study evaluates KPI's gathered from field measurements, using a statistical approach to establish the performance and determine the present condition of the quality of service offered by a 4G LTE network in Port Harcourt, Nigeria. In this study, a drive test approach was adopted to measure the KPI's and analysis was achieved with the use of TEMs Discovery software adopting a statistical approach. The result showed the value range of the measured KPI's were; RSSI (-90, -49.7dBm), RSRP (-117.7, -68.6 dBm), RSRQ (-14.2, -22.8dB) representing minimum and maximum values. The probability distribution of the various KPI's showed that the best signal ranges were distributed as $38.21 \%, 69.63 \%$ and $65.63 \%$ for RSSI, RSRP and RSRQ respectively. The KPI parameters were within the acceptable range, though require optimization to provide better service for a greater population.
\end{abstract}

Keywords: QOS, KPI, Probability distribution, Optimization

\section{Introduction}

Access to Mobile connectivity has today become an integral part of man's existence. The proliferation of wireless technologies has transformed the way information exchange is carried out [1]. Except for voice calls which was the primary aim in the development GSM, other attractive value-added services such as Short Message Service (SMS) and Internet services have been made available by the advancement of mobile technologies. The internet and web have further enhanced the pace in the development of e-learning platforms and the provision of several applications for mobile banking, e-mail, social networking, teleconferencing [2].

The implementation of $4 \mathrm{G}$ network was achieved with the packet switching technology which aimed at meeting the growing demand of a large subscriber base with mobile connectivity anytime and anywhere, a better quality of the service, and an improved capacity of traffic flow through networks [3]. The intent of using these frequencies is to provide consumers with efficient mobile network data at high speed, offer superior quality of service better than the existing technologies [4]. This advancement has led to a high level of success in data connection on the mobile network which has resulted in an upsurge in the number users [5], and as such requires proper monitoring to ensure the QOS is maintained [6]. 
Maintaining the quality of service for mobile users has become a major challenge, given that several factors affect the transmitted signal. Factors such as the rate of mobility of users and the rate at which calls are made daily contribute to the drop in quality of service. These challenges require adequate and continuous monitoring of key performance indicators for early detection of areas with degraded service.

With the need to meet and sustain the growing demands of mobile users, several approaches have been adopted. We adopt the approach of generating and analyzing key performance indexes of the deployed $4 \mathrm{G}$ network within the area of study. This study will assist in determining the state of the network in real time, provide information on the handoff and adequate information on how to enhance the network for improved coverage and capacity.

In this paper, we present the analysis of some KPI's of a $4 \mathrm{G}$ network in real time. The captured KPI's include RSSI, RSRP, RSRQ, BLER, DL Throughput and UL Throughput. These KPIs were measured from a 4G LTE at a frequency of $1800 \mathrm{MHz}$.

We divide the paper as follows: Section one provides an introduction, section two, review of literatures, three provides the methodology adopted, four shows the results obtained and five shows the conclusion.

\section{Review of Literature}

Various research works have been done in this area to ascertain the quality of service using KPI'S. We thus present works related to this study;

According to [7] the authors analyzed the performance of KPI's in fourth-generation Network in Smart cities. They looked at KPI's which were related to the performance of the chosen network. They adopted the drive test for data collection using Genex Probe V16. The result was analyzed and presented using probability distribution functions.

The work of [2] examined the quality of service of GSM service provider MTN in Abuja covering the eagles square during and after a political gathering. Five KPI's were utilized namely (CCSF, TCH-CR, CSSR, DCR, HOSR). Results showed that some deviations from the recommended values were obtained during and after the event. The authors opined that the QoS required some improvement to arrest further degradation. The authors in [8] carried out research on the QoS of Nigerian GSM operators using a real time methodology. This study was carried out in Abuja Metropolis using KPI's such as CCR, CSSR, CDR, CHSR, SDCCH. The results obtained showed agreement with existing works on QoS status in Nigeria based on the above KPIs. The work of [9], carried out a research work titled KPI measurement on the $4 \mathrm{G}$ network within the University of Ilorin campus. Their work was geared at obtaining the throughput and other KPI's. They adopted a walk test approach for data collection where file upload, download or video streaming was carried out. It was observed that the $4 \mathrm{G}$ test showed no exceptional result. They opined that the $4 \mathrm{G}$ Network within the University of Ilorin campus needed optimization to cater for the population growth of students experienced.

According to [10], they embarked on a network performance evaluation geared at ascertaining the level of degradation on the WCDMA networks within Owerri metropolis. MTN and Airtel Networks were chosen as mobile networks to be evaluated. In this, two networks were evaluated empirically to determine their performance using selected Key Performance Indicators (KPIs). The result showed that only MTN network along FUTO, Wetheral and Onitsha roads were in agreement with the NCC target value on CCSR. Also, MTN network along Onitsha Road slightly met the NCC target value on CSSR and network accessibility. The work of [11] carried out performance studies on fourth generation LTE around shopping malls and schools in Lagos State. Huawei Technologies drive test (DT) equipment was used to capture data at an operating frequency of $1876.6 \mathrm{MHz}$. Key performance indicators monitored were listed as RSSI, RSRQ, RSRP, SINR and Throughput. MapInfo tool was used to extract Test results and analysis done in MATLAB. The measured data was fitted using a ninth order polynomial to obtain fitness. The result showed a maximum RSRP of $2.49 \mathrm{dBm}$, PDCP Throughput of $1867.41 \mathrm{bps}$, PCC PHY 
Throughput of $2256.35 \mathrm{bps}$ in BS 3, RSRQ of $0.37 \mathrm{dBm}$, RSSI of $2.30 \mathrm{dBm}$ in BS 1, and SINR of $2.15 \mathrm{~dB}$ in BS 2. They concluded that the obtained results compared favorably with that provided by NCC. The work of [12], described the development of an automatic artificial neural network (ANN) predictive QoS model. They adopted five key performance indicators (KPIs); CSSR, CD, SDCCH, TCH and CCR and data was collected from a GSM network operator. The collected data from KPI parameters were used to develop a mathematical model that was transformed into the proposed automatic QoS predicted model using ANN. The developed QoS prediction model, was found to be accurate and could perform well when compared with the existing manual approach in use by the Nigerian Communications Commission. The work of [13], carried out a study on a 4G LTE communication base station installed in a rural area of Peru with an aim to identify the qualityof-service parameters. They adopted the Descriptive-Correlational type of research. Research data was collected from $4 \mathrm{G}$ base stations in the $700 \mathrm{MHz}$ band. The instrument used for the investigation were the technical measurement reports, where the characteristics of the quality parameters of a Mobile Telephone Communications Base Station such as signal level, signal SRN and signal quality were provided. The results obtained shows that, in relation to the quality parameters, it can be affirmed that the results comply with what was showed by the investigation of the Canary Islands Government and are within an acceptable range.

\subsection{Key performance Indicators for LTE}

Performance evaluation through Drive Test (DT) for LTE spectrum evaluation presents reports with different measurements parameters. They are used to determine the quality of service rendered by a chosen network. The chosen parameters are RSSI, RSRQ, RSRP, and Throughput. Though in 4G Network, the KPI's are defined differently compared to that used for $2 \mathrm{G}$ and $3 \mathrm{G}$. This is attributed to the use of packet switching technology [14], [11].

\subsubsection{RSSI}

Received Signal Strength Indicator (RSSI) this parameter describes the overall power received by the UE over the whole LTE and this includes the power of the serving cell, interference, and noise power channel. Information about the interference and noise are determined with the aid of the RSSI.

\subsubsection{RLC Throughput}

This is the total amount of data bits that are successfully transferred over a communication link in a given amount of time. This is measured over different distances and the values vary. Other measures that could impact on the productivity of the system include speed, which is determined by the workload at a given response time comparing when the request and response is received [15].

\subsubsection{Reference Signal Received Power (RSRP)}

Reference signal received power (RSRP) is the average power which transports the reference signals for specific cells in a specific bandwidth. The values of RSRP range from $-140 \mathrm{dBm}$ to $-44 \mathrm{dBm}$. The RSRP determine certain processes as handoff and cell selection. Information about the signal power is given by the RSRP. RSRP can be mathematically described by equation (1) [11].

$$
\operatorname{RSRP}(\mathrm{dBm})=\frac{P_{o}}{N}
$$

where,

$\mathrm{P}_{\mathrm{o}}$ represents received power

$\mathrm{N}$ represents elements of the LTE signal carrier bandwidth 


\subsubsection{Reference Signal Received Quality (RSRQ)}

This parameter plays a vital role in determining the quality of the signal. They range from $-19.5 \mathrm{~dB}$ to $-3 \mathrm{~dB}$ with a half $\mathrm{dB}$ step. When ranking cells for handover and cell reselection, the RSRQ is used. RSRQ can be expressed as equation (2) [16]:

$$
R S R Q=10 \log _{10}(N)+R S R P(d B m)-R S S I(d B m)
$$

\section{Methodology}

\subsection{Measurement Environment}

The study area includes Artillery and Choba (University of Port Harcourt, Abuja campus) in Rivers State. Artillery is located on Latitude $4^{\circ} 50^{\prime} 38^{\prime \prime} \mathrm{N}$ and Longitude $7^{\circ} 02^{\prime} 20^{\prime \prime} \mathrm{E}$ within the metropolis of Port Harcourt, which is classified as an urban area owing to the presence of high-rise buildings and high-level traffic of persons. Choba is located on Latitude $4^{\circ} 54^{\prime} 09^{\prime \prime} \mathrm{N}$ and longitude $6^{\circ} 55^{\prime} 14^{\prime \prime} \mathrm{E}$ and classified as a suburban environment with high mobility of persons due to the presence of the school located within the environment.

\subsection{Data collection and analysis}

Data was collected through drive test, using various measurement tools and devices. A vehicle with the measurement instrument installed in it drove through a defined route at a speed of $40 \mathrm{~km} / \mathrm{hr}$. An Acer Aspire personal computer installed with TEMS investigation software was deployed. The various Key performance indicators were captured and stored as logs in the personal computer system during active download. Huawei LTE modem and a Samsung Galaxy S5model (SM G900i) with 4G capability were used for download during the drive test. A GPS unit was used to capture the distance traveled, longitude and latitude of the area. Acquired data was analyzed with the TEMS Discovery Professional (10.0.1 Build: 5007).

\subsection{Measurement Parameters}

The measurement parameters for this study are shown in Table 1.

Table 1. Measurement Parameters

\begin{tabular}{cc}
\hline Measurement Parameters & Values \\
\hline Operating Frequency & 1800 \\
UE Transmit power & $14.2($ Min) 22.8 (Max) \\
Receiver Height & $15 \mathrm{~m}$ \\
Transmitter Height & $35 \mathrm{~m}$ \\
\hline
\end{tabular}

\section{Result and Discussion}

In this section, we present a summary of results gathered from the measurement campaign. The results of the key performance indicators measured are presented: Reference Signal Received Power (RSRP), Reference Signal Received Quality (RSRQ), Received Signal Strength Indicator (RSSI), RLC Throughput (DL), RLC Throughput (UL), PDSCH BLER is presented. We adopt a statistical approach to present the performance of the investigated 4G LTE network as shown in Table 2 and Table 3 respectively. 
Table 2. Statistical Summary of key Metrics for RF conditions

\begin{tabular}{ccccccc}
\hline Name of Key Metrics & Bin Count & Mean & Min. & Max. & St. Dev. & Median \\
\cline { 2 - 6 } & & & & & & \\
Top Cell Channel RSSI $(\mathrm{dBm})$ & 2018 & -71.29 & -90 & -49.7 & 6.83 & -71.9 \\
Top Cell RSRP $(\mathrm{dBm})$ & 2018 & -96.01 & -117.7 & -68.6 & 7.09 & -96 \\
Top Cell RSRQ $(\mathrm{dB})$ & 1996 & -15.46 & -27.1 & -5.8 & 3.13 & -15.5 \\
UE TX Power $(\mathrm{dBm})$ & 10 & 19.65 & 14.2 & 22.8 & 2.81 & 20.3 \\
\hline
\end{tabular}

Table 3. Statistical Summary of key Metrics for Performance Indicators

\begin{tabular}{ccccc}
\hline Name of Key Metrics & Bin Count & Mean & Max & St. Dev \\
\hline PDSCH BLER (\%) & 2 & 3.85 & 7.69 & 3.85 \\
RLC Throughput DL (kbps) & 6 & 0.04 & 0.25 & 0.09 \\
RLC Throughput UL (kbps) & 6 & 0.03 & 0.2 & 0.07 \\
\hline
\end{tabular}

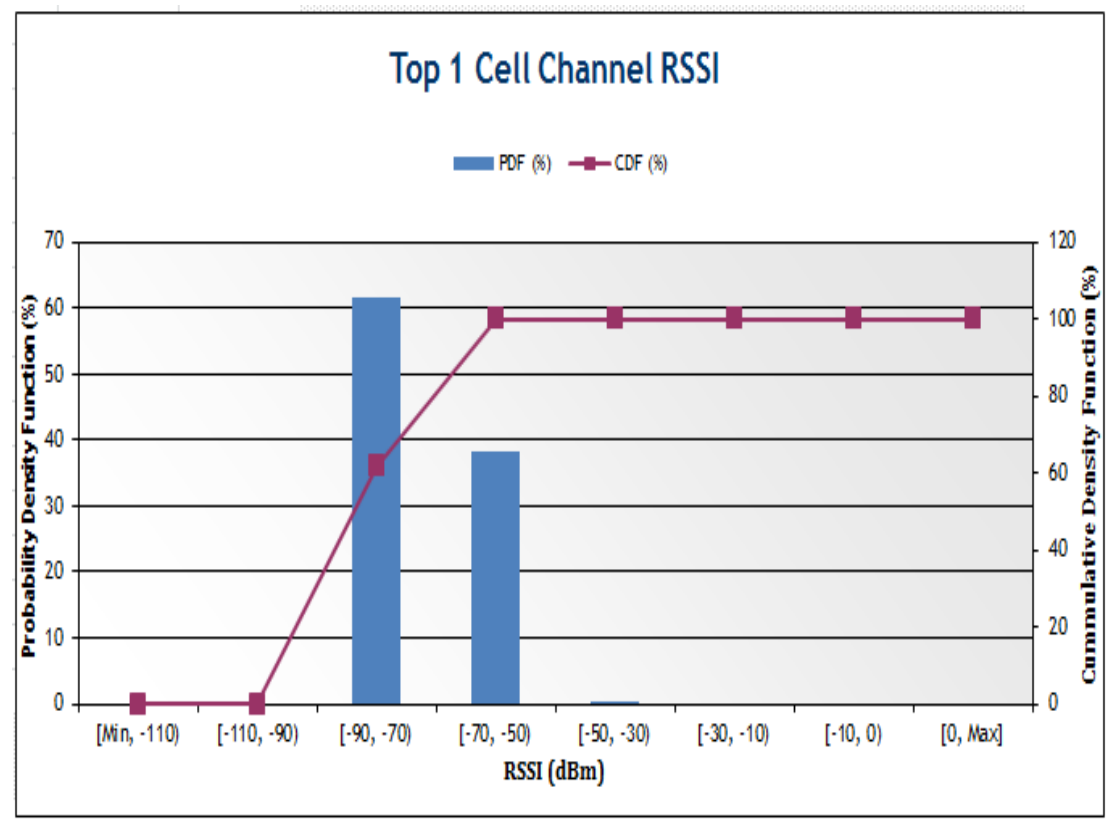

Figure 1. Graph of PDF, CDF against RSSI

The statistical analysis in Figure 1 shows the probability distribution of the measured RSSI of the $4 \mathrm{G}$ network signal. The probability density of $61.69 \%, 38.21 \%$ and $0.1 \%$ were recorded for RSSI range $(-90,-70 \mathrm{dBm}),(-70,-50 \mathrm{dBm})$ and $(-50,-30 \mathrm{dBm})$ respectively. For the RSSI range $(-90,-70 \mathrm{dBm})$, the distribution shows $61.69 \%$. which showed that a greater portion of the area experienced fair signal coverage strong enough to provide fast and reliable data speed. The RSSI range of $(-70,-50 \mathrm{dBm})$, the distribution of $38.21 \%$ probability density was recorded. This range of signal offers the best RSSI and is strong enough to offer good data speed. The $(-50,-30 \mathrm{dBm})$ RSSI range recorded the least in distribution of $0.1 \%$. 


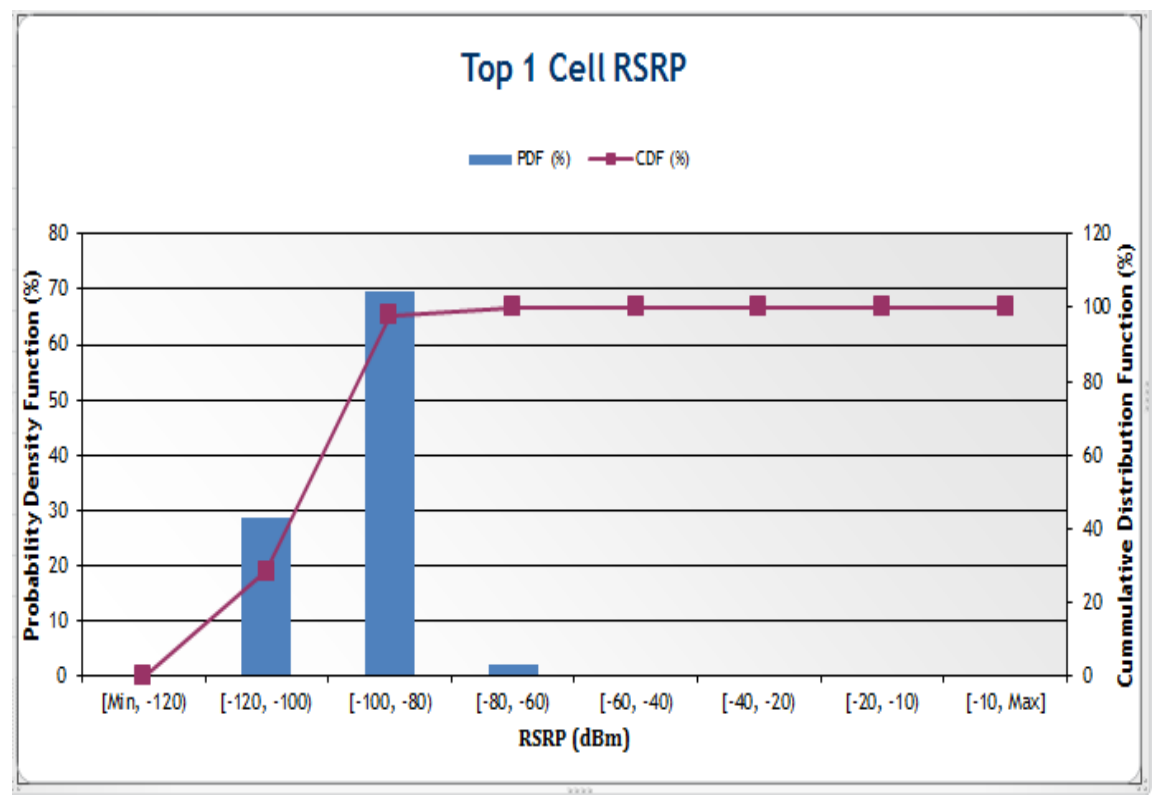

Figure 2. Graph of PDF, CDF against RSRP

The distribution of RSRP is shown in Figure 2. The graphical distribution analysis shows that the recorded RSRP values in are in three different ranges; $(-120,100 \mathrm{dBm}),(-$ $100,-80 \mathrm{dBm})$ and $(-80,-60 \mathrm{dBm})$ respectively. The RSRP range $(-120,-100 \mathrm{dBm})$ has a distribution of $28.54 \%$. This range of signal is poor and capable of causing drop outs. The signal range of $(-100,-80 \mathrm{dBm})$ has a distribution of $69.47 \%$. This range of signal is strong and will most likely offer reliable and good data speed. The third category is within the range of $(-80,-60 \mathrm{dBm})$. The range offers the least distribution and could provide good data speed.

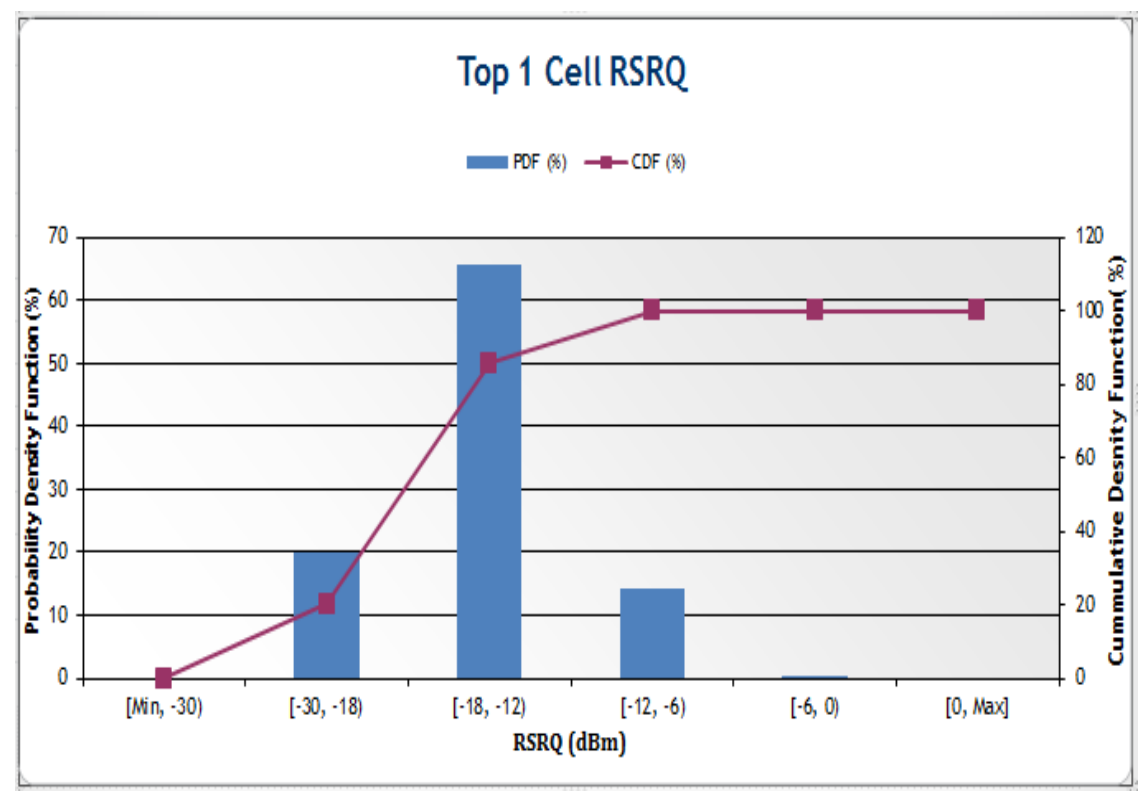

Figure 3. Graph of PDF, CDF against RSRQ

Figure 3 shows the distribution of the RSRQ signal provided by the 4G LTE. The distribution of the RSRQ signals shows that range $(-30,-18 \mathrm{dBm}),(-18,-12 \mathrm{dBm})$ and $(-12,-$ $6 \mathrm{dBm})$ are $20 \%, 65.63 \%$ and $14.23 \%$ respectively. The best signal is found in the category of $(-18,12 \mathrm{dBm})$ with a probability density of $65.63 \%$ of the entire population. This signal 
range could offer strong signal with maximum data speed. The probability density of signals within the range of $(-30,-18 \mathrm{dBm})$ is $20 \%$ followed by $(-12,-6 \mathrm{dBm})$ which is $14.23 \%$. From the distribution, the population that requires handover could be shown as $20 \%$ depicting signals within the signal range $(-30,-18 \mathrm{dBm})$.

\section{Conclusion}

This paper focused on evaluating the performance of KPI's of a $4 \mathrm{G}$ network in Port Harcourt. The performance of a $4 G$ LTE network has been evaluated using measured KPI's. Key parameters analyzed are the RSSI, RSRQ and RSRP. A greater distribution of the RSSI signal was categorized as being fair, though they were within the recommended range. While the RSRQ has a greater distribution classified to be good. The RSRP analysis showed a greater distribution of the good signal and the least distribution fair to offer good and reliable service. Though the throughput showed a very negligible variation in both Uplink and downlink measurements. The results showed that the $4 \mathrm{G}$ network parameters were not out of the recommended range, they network required optimization to ensure the QOS is improved upon.

\section{Reference}

[1] Jiménez, J., \& Ochovo., J. (2017). Comparative Evaluation of Mobile Networks. Polytechnic University of Madrid, Madrid.

[2] Lawal B. Y., Ukhurebor K. E., Adekoya M. A., \& Aigbe E.E (2016). Quality of service and performance analysis of a GSM network in eagle Square, Abuja and its environs, Nigeria. International Journal of Scientific \& Engineering Research, 7(8), 1992-1999. ISSN 2229-5518

[3] Miyim, A. M., \& Wakili, A. (2019). Performance evaluation of LTE networks. 2019 15th International Conference on Electronics, Computer and Computation (ICECCO). https://doi.org/10.1109/icecco48375.2019.9043271

[4] Chang, BJ., Liang YH., \& Su, SS (2015). Analysis of QOS- based relay deployment in 4G LTE-a wireless mobile relay networks. In the $21^{\text {st }}$ Asia-Pacific Conference on Communications, IEEE, Koyoto: Japan: 62-67.

[5] Kuboye, B. M. (2017). Evaluation of broadband network performance in Nigeria. International Journal of Communications, Network and System Sciences, 10(09), 199-207. https://doi.org/10.4236/ijcns.2017.109011

[6] Almazroi, A. A. (2018). Performance analysis of 4G broadband cellular networks. International Journal of Advanced and Applied Sciences, 5(9), 12-17. https://doi.org/10.21833/ijaas.2018.09.003

[7] moize, A. L., Orolu, K., \& Atayero, A. A. (2020). Analysis of key performance indicators of a 4G LTE network based on experimental data obtained from a densely populated smart city. Data in Brief, 29, 105304. https://doi.org/10.1016/j.dib.2020.105304

[8] Nochiri, I.U., Osuagwu C. C., Okafor K.C. (2014). Empirical analysis on the GSM network KPIs using real time methodology for a novel network integration. Progress in Science and Engineering Research Journal, 2(3), 92-107. ISSN 2347-6680 (E)

[9] Oje, A. A., \& Edeki, S. O. (2021). Performance analysis of service users' perception of mobile network quality in the learning settings. Journal of Physics: Conference Series, 1734, 012032. https://doi.org/10.1088/17426596/1734/1/012032

[10] Onyenwe, E.M., Nosiri, O. C., Nkwachukwu, C., \& Agubor, C. K. (2018). Performance evaluation of WCDMA networks in selected Geolocations using structured questionnaire and empirical analysis methods. International Journal of Advances in Scientific Research and Engineering, 4(12), 62-71. https://doi.org/10.31695/ijasre.2018.33006

[11] Imoize, A.L \& Adegbite, O.D. (2018). Measurements-based performance analysis of a 4G LTE network in and around shopping malls and campus environments in Lagos, Nigeria. Arid Zone Journal of Engineering, Technology and Environment, Vol. 14(2), 208225.

[12] Popoola, J. J., \& Areo, A. E. (2020). Modeling and development of a novel quality of service prediction model for global system for mobile communications network using artificial neural networks. Journal of Applied Science E Process Engineering, 7(2), 510523. https://doi.org/10.33736/jaspe.2405.2020

[13] Chamorro-Atalaya, O., Pizarro-Mayta, E., \& Arce-Santillan, D. (2020). Evaluation of the quality parameters of a 4G-LTE communications base station, installed in a rural area of Peru. Advances in Science, Technology and Engineering Systems Journal, 5(1), 71-76. https://doi.org/10.25046/aj050109

[14] Afroz, F., Subramanian, R., Heidary, R., Sandrasegaran, K., \& Ahmed, S. (2015). SINR, RSRP, RSSI and RSRQ measurements in long term evolution networks. International Journal of Wireless \& Mobile Networks, 7(4), 113-123. https://doi.org/10.5121/ijwmn.2015.7409

[15] Shah, H., \& Bansode, R. (2016). Performance evaluation and measurement for energy efficient wireless networks. Procedia Computer Science, 79, 971-977. https://doi.org/10.1016/j.procs.2016.03.123

[16] Elechi, P., Orike, S. and Akujobi, E.C. (2021), Minimization of Handoff Failure in a Heterogeneous Network Environment using Multi Criteria Fuzzy System, Journal of Telecommunication, Electronic and Computer Engineering, 13(2), 25-33. 